Int. J. Electrochem. Sci., 13 (2018) $8084-8093$

\title{
Corrosion Behaviour of AZ63 Magnesium Alloy in Natural Seawater and 3.5 wt.\% NaCl Aqueous Solution
}

\author{
Lihui Yang ${ }^{1,2,3, *}$, Cunguo Lin $^{2}$, Haiping Gao ${ }^{2}$, Weichen $\mathrm{Xu}^{1,3}$, Yantao $\mathrm{Li}^{1,3}$, Baorong Hou ${ }^{1,3}$ and \\ Yanliang Huang ${ }^{1,3}$ \\ ${ }^{1}$ Key Laboratory of Marine Environmental Corrosion and Bio-fouling, Institute of Oceanology, \\ Chinese Academy of Sciences, Qingdao 266071, China \\ ${ }^{2}$ State Key Laboratory for Marine Corrosion and Protection, Luoyang Ship Material Research Institute \\ (LSMRI), Qingdao 266101, China \\ ${ }^{3}$ Open Studio for Marine Corrosion and Protection, Qingdao National Laboratory for Marine Science \\ and Technology, Qingdao 266237, China \\ *E-mail: lhyang@qdio.ac.cn
}

doi: $10.20964 / 2018.08 .32$

Received: 23 January 2018 / Accepted: 15 May 2018 / Published: 5 July 2018

In this study, the corrosion behaviour of AZ63 magnesium alloy was investigated in natural seawater and neutral 3.5 wt.\% $\mathrm{NaCl}$ aqueous solution. The electrochemical processes were studied using potentiodynamic polarization. The composition and morphology of the alloys and corrosion products formed were studied using X-ray diffraction (XRD) and scanning electron microscopy (SEM). The experimental results highlighted the differences between the corrosion mechanisms of AZ63 magnesium alloy in natural seawater and that in $3.5 \mathrm{wt} . \% \mathrm{NaCl}$ solution. The corrosion products formed in the seawater primarily consisted of $\mathrm{CaCO}_{3}$ and $\mathrm{Mg}(\mathrm{OH})_{2}$, while the corrosion products formed in the 3.5 wt. $\% \mathrm{NaCl}$ solution primarily consisted of $\mathrm{Mg}(\mathrm{OH})_{2}$ and $\mathrm{Mg}_{2}(\mathrm{OH})_{3} \mathrm{Cl} \cdot 4 \mathrm{H}_{2} \mathrm{O}$. The results of hydrogen evolution, weight loss and potentiodynamic polarization tests showed that the AZ63 magnesium alloy samples had better corrosion resistance in natural seawater than in $3.5 \mathrm{wt} \%$ $\mathrm{NaCl}$ aqueous solution.

Keywords: AZ63 magnesium alloy; corrosion behaviour; polarization curve; seawater

\section{$\underline{\text { FULL TEXT }}$}

(C) 2018 The Authors. Published by ESG (www.electrochemsci.org). This article is an open access article distributed under the terms and conditions of the Creative Commons Attribution license (http://creativecommons.org/licenses/by/4.0/). 